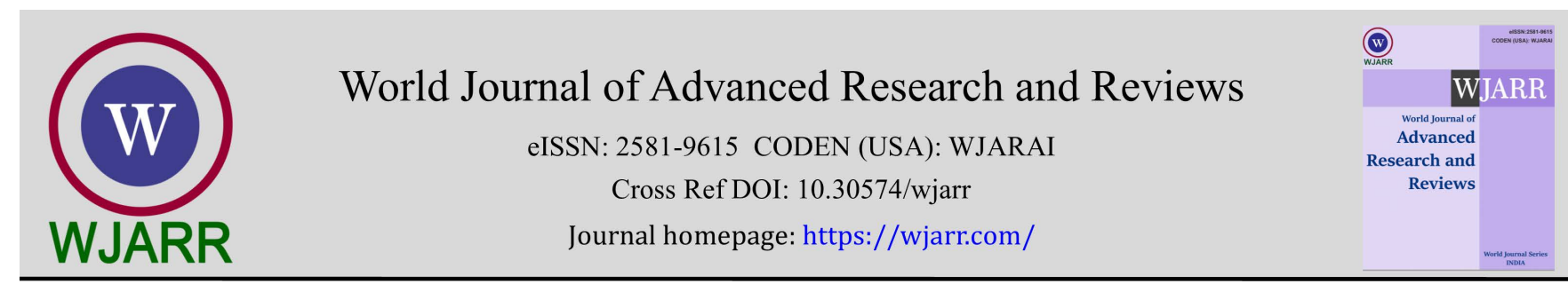

(RESEARCh ARTiCle)

\title{
Interventional treatment of Anal Fistula: A Retrospective Analysis
}

\author{
Duran Y ${ }^{1}$, Polat IF 2, Gokce H ${ }^{3}$, Gokce FS ${ }^{4}$, Bali I ${ }^{1}$, Benek S ${ }^{1}$ and Polat FR 1,* \\ ${ }^{1}$ TNK University Medical Faculty, Division of General Surgery, Tekirdag- Turkey. \\ 2 TNK University Engineering Faculty, Division of Machinery (std), Tekirdag- Turkey. \\ ${ }^{3}$ Atlas University Medical Faculty, Division of General Surgery, İstanbul- Turkey. \\ ${ }^{4}$ Balıklı Rum Hospital, Department of general surgery, Istanbul- Turkey.
}

World Journal of Advanced Research and Reviews, 2021, 10(02), 225-228

Publication history: Received on 16 March 2021; revised on 19 April 2021; accepted on 22 April 2021

Article DOI: https://doi.org/10.30574/wjarr.2021.10.2.0171

\begin{abstract}
Introduction: Anal fistula is a benign anorectal disease. Infection of Hermann and Desfosses anal glands is responsible for the formation of abscesses and/or fistulas. The main treatment is surgery but recurrence and sometimes incontinence are frequently observed. So to choose surgical methods of anal fistula treatment is very important.

Aim: The aim of this retrospective study was to evaluate the reliability and feasibility of Video-assisted anal fistula treatment (VAAFT) at the anal fistula surgery.

Materials and Methods: A retrospective analysis was performed on data collected during a 11-year period (2008-2019) from 52 patients who underwent fistulotomy with loose seton technique. The male to female ratio was 3:1 and the mean patient age was 48.34 years.

Results: Mortality, recurrence, complications rate were $0 \%$. Though the patients were scheduled as day-surgery cases, the average duration of hospital stay was 1.18 days. Quality of life index (QOLI) for these patients were often be improved by treating their fistula.

Conclusion: The appropriate treatment for anal fistula is dependent upon the anatomy and the location of the fistula tract. Detection of the inner mouth is the touchstone in the treatment of anal fistula. It could be determined location of inner mouth of the anal fistula easily with transparent anoscope guideline. VAAFT seems to be a safe and effective technique for treating perianal fistula without recurrence and anal incontinence.
\end{abstract}

Keywords: Anal fistula; VAAFT; Loose Seton Technique; Treatment

\section{Introduction}

Anal fistulas continue to be a problem for patients and surgeons alike despite scientific advances. While patient and anatomical characteristics are important to surgeons who are evaluating patients with anal fistulas, their development and persistence likely involves a multifaceted interaction of histological, microbiological, and molecular factors1. Anal fistula is a common benign condition that typically describes a miscommunication between the anorectum and the perianal skin, which is develop after acute anorectal abscess2. Infection of Hermann and Desfosses anal glands is responsible for the formation of abscesses and/or fistulas3. The main treatment is surgery. The ideal surgical treatment for anal fistula should eradicate sepsis and promote healing of the tract, whilst preserving the sphincters and the mechanism of continence 4 . There are different surgical methods of anal fistula treatment. Treatment of this benign

\footnotetext{
${ }^{*}$ Corresponding author: Polat FR

TNK University Medical Faculty, Division of General Surgery (senior author), Tekirdag- TURKEY..
}

Copyright (C) 2021 Author(s) retain the copyright of this article. This article is published under the terms of the Creative Commons Attribution Liscense 4.0. 
disease can affect faecal continence5. Recurrence is frequently observed due to the inability to identify inner mouth of the fistula during surgery. Detection of the inner mouth is the touchstone in the treatment of anal fistula. The study is to discuss the effectiveness of transparent anoscope guideline in the detection inner mouth of fistula. The aim of this retrospective study was to evaluate the reliability and feasibility of the VAAFT at the anal fistula surgery.

\section{Material and Methods}

This is a retrospective study that involves data collection from medical records of patients undergoing fistulotomy with loose seton technique. The records of all patients who underwent anal fistulotomy between September 2008 and March 2019 in our institutions (Istanbul Balıklı Rum Hospital and Tekirdag Namik Kemal University Hospital) were retrieved. During this period, a total of 52 patients underwent anal fistulotomy with loose seton technique. The male to female ratio was 3:1 (37 vs 15) and the mean patient age was 48.34 (range 25-85) years. Pelvic Magnetic Resonance was performed in all patients before surgery. All patients scheduled for anal fistulotomy were admitted the day before, and were allowed to have food and liquids until 6 hour before the operation.

Technique 4, 5, 6, 7, 8: For complete relaxation of the anal sphincter muscles; deep general anesthesia is applied to all cases. No pressure is applied to the anal margin zone during material injection. Hydrogen peroxide, milk and blue dye are used for identification and irrigation of the fistula tract. For irrigation gently and firstly milk or hydrogen peroxide is injected at the outer mouth of anal fistula. Later, the milk from the inner mouth of fistula is observed with a transparent anoscope. Secondly blue dye injected at the outer mouth of anal fistula. Then, the milk from the inner mouth of fistula is observed with a modified transparent anoscope (Figure 1). Then, the guide wire which is sent at the outer mouth of the fistula was observed through the inner mouth of the fistula. The rubber band is passed through the fistula tract and tied with guide wire guided.

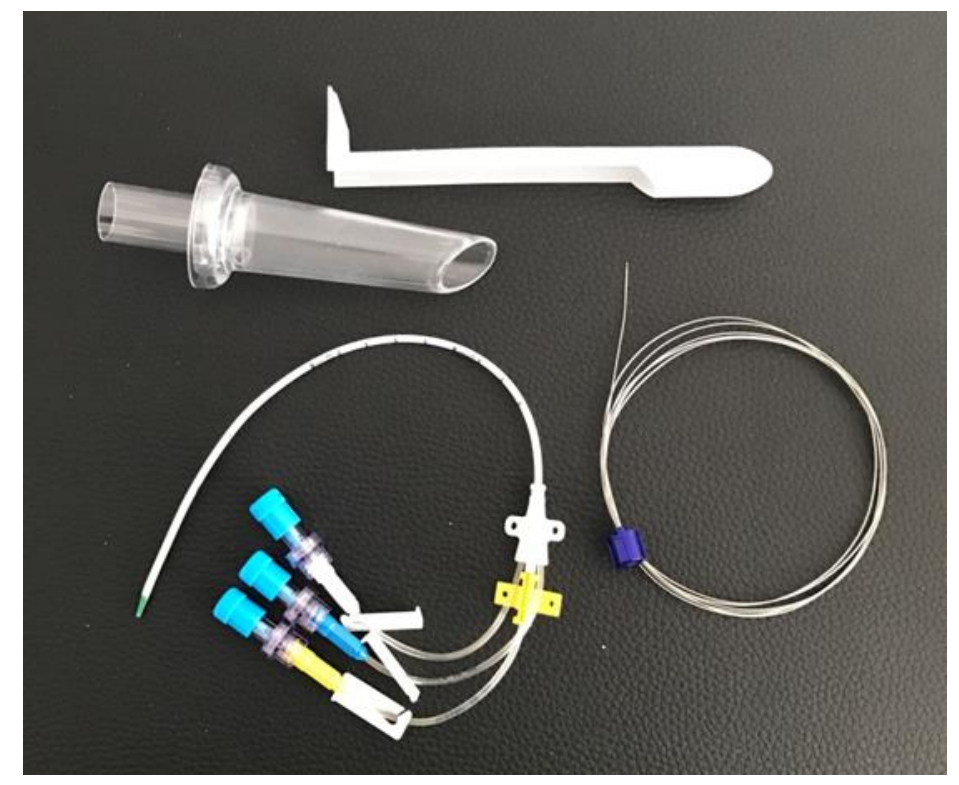

Figure 1 Modified transparent anoscope and Guides

\section{Result}

Mortality and morbidity rate was $0 \%$. The patients were followed up for an average of 5(4->9) months. Loose seton technique was performed successfully in all 52 patients. Mortality and morbidity rate was $0 \%$. The median operation time was 40-90 minutes. Internal mouth of fistula were identified in all cases. No any complications were observed in the cases. Complete healing without recurrence was achieved in 50 patients (96\%) after 4 months of follow-up. No fecal incontinence was observed. Furthermore, a significant improvement in Quality of Life Index (QOLI) score was observed from preoperative baseline (mean, 89.5) to 3-month follow-up (mean, 101.2; $\mathrm{p}<0.001$ ), and this increase was maintained at 9-months follow-up (mean, 105.6; $\mathrm{p}<0.001$ ). 


\section{Discussion}

Anal fistulas continue to be a problem for patients and surgeons alike despite scientific advances 1 . The presence of a perianal abscess that contains gut flora commonly leads to the development of anal fistula 1.

The glands of Hermann and Desfosses, located in the thickness of the anal canal, drain into proximal of the dentate line. Infection of these anal glands is responsible for the formation of abscesses and/or fistulas3. Fistulas also may be due to crohn disease, cancer, trauma, tuberculosis, or radiation 6.

The appropriate treatment for an anal fistula is dependent upon the anatomy and the location of the fistula tract7. The Salmon-Goodsall rule is of assistance in identifying the direction of the tract. The Salmon-Goodsall's rule states that if the anus is bisected by a line in the frontal plane, an external opening anterior to the line will connect to an internal opening by a short, direct fistula tract. However, if the external opening is located posterior to this imaginary line, the fistula tract follows a curved course to the crypt in the posterior midline 6,7. This rule, while useful, is not infallible.

The main treatment is surgery. The ideal surgical treatment for anal fistula should eradicate sepsis and promote healing of the tract, whilst preserving the sphincters and the mechanism of continence4. Several surgical procedures have been developed, but the risks of recurrence and impairment of continence still seem to be an unresolved issue8. Women with anterior fistula or previous obstetric injury as well as patients with pre-existing incontinence or specific risks such as previous local irradiation or co-existing Crohn's disease are also at significant risk of incontinence and poor outcome 4,9. The key to successful treatment are the eradication of the primary track and detection of the inner mouth of fistula. There are different surgical methods of anal fistula treatment.

At the stage of fistula, treatment has two sometimes conflicting objectives: effective drainage and preservation of continence. These two opposing constraints explain the existence of two therapeutic concepts3. On one hand the layingopen of the fistulous tract (fistulotomy) in one or several operative sessions remains the treatment of choice because of its high cure rates. On the other hand obturation with biological components preserves sphincter function but suffers from a higher failure rate, or surgical closure with tract ligation3. Placement of a soft, noncutting seton permits resolution of surrounding inflammation while preserving sphincter musculature6. In here, the key to successful treatment is detection of the inner mouth.

VAAFT permits examination of the ano-rectal region and also with it can be obtained direct vision of inner mouth of the fistula. Transparent anoscope guideline allows visualization of the mucosal surface of the anorectal region. So, Surgeon could determine location of inner mouth of the anal fistula with transparent anoscope guideline 10.

The seton placement has been advocated either loose, to control infection, or cutting through the sphincter muscle gradually or as a bridge between two separate partial fistulotomies 4,11,12. The short-term healing rate of loose seton ranges between $44 \%$ and $83 \% 4,13,14,15$. Cutting setons have been used in the attempt to slowly divide the sphincters while allowing scarring to occur and limit disruption of the muscular ring, with recurrence rates from $22 \%$ to $39 \%$ $4,16,17$. We used 'loose seton technique' with transparent anoscope guideline after colonoscopy 16 . The inner mouth of fistula were determined in the all cases. No recurrence or incontinence was observed in any case.

\section{Conclusion}

As a result; the use of transparent anoscope guideline during the surgical treatment of anal fistula is an effective method of preventing recurrence and anal incontinence. We recommend that VAAFT be attempted on all patients underwent surgery. However, prospective control trials are needed to be used in routine.

\section{Compliance with ethical standards}

\section{Disclosure of conflict of interest}

The authors have no conflict of interest to declare. 


\section{Author contributions}

Concept -, Design-, Supervision -, Resource -, Materials -, Data Collection and/or Processing - Polat FR, Gokce FS; Analysis and/or Interpretation - Literature Search -, Writing -, Critical Reviews -Duran Y, Polat FR, Gokce FS, Gokce H, Bali I, Benek S; Modified transparent anoscope; Polat IF.

\section{References}

[1] Sugrue J, Nordenstam J, Abcarian $\mathrm{H}$, et al. Pathogenesis and persistence of cryptoglandular anal fistula: a systematic review. Tech Coloproctol. 2017; 21(6): 425-432.

[2] Zubaidi AM. Anal fistula. Past and present. Saudi Med J. 2014; 35(9): 937-944.

[3] Pigot F. Treatment of anal fistula and abscess. J Visc Surg. 2015; 152(2 Suppl): S23-S29.

[4] Limura E, Giordano P. Modern management of anal fistula. World J Gastroenterol. 2015; 21(1): 12-20.

[5] Owen HA, Buchanan GN, Schizas A, Cohen R, Williams AB. Quality of life with anal fistula. Ann R Coll Surg Engl. 2016; 98(5): 334-338.

[6] Sean C. Glasgow, James W. Fleshman. Colon, Rectum, and Anus. Mary E. Klingensmith,(Editor). The Washington Manual of Surgery. Washington. The, 5th Edition. Lippincott Williams \& Wilkins. 2008; 214-238.

[7] Anne Y Lin, James W Fleshman, Jr. Benıgn Disorders Of The Anorectum (Pelvic Floor, Fissures, Hemorrhoids,And Fistulas). Michael J. Zinner, Editors. Abdominal operatıons. Tenth edition. London: Prentice Hall International Inc. 2012; 8: 803-832.

[8] Amato A, Bottini C, De Nardi P, et al. Evaluation and management of perianal abscess and anal fistula: a consensus statement developed by the Italian Society of Colorectal Surgery (SICCR). Tech Coloproctol. 2015; 19(10): 595606.

[9] Whiteford MH, Kilkenny J, Hyman N, Buie WD, Cohen J, Orsay C, Dunn G, Perry WB, Ellis CN, Rakinic J. Practice parameters for the treatment of perianal abscess and fistula-in-ano (revised). Dis Colon Rectum. 2005; 48: 13371342.

[10] Mark L. Welton, George J. Chang, Andrew A Shelton. Anorectum. Gerard M. Dohery, Editor. Current Surg diagnosis. Twelfty edition. McGraw-Hill. 2006: 739-766.

[11] Malouf AJ, Buchanan GN, Carapeti EA, Rao S, Guy RJ, Westcott E, Thomson JP, Cohen CR. A prospective audit of fistula-in-ano at St. Mark's hospital. Colorectal Dis. 2002; 4: 13-19.

[12] Nwaejike N, Gilliland R. Surgery for fistula-in-ano: an audit of practise of colorectal and general surgeons. Colorectal Dis. 2007; 9: 749-753.

[13] Eitan A, Koliada M, Bickel A. The use of the loose seton technique as a definitive treatment for recurrent and persistent high trans-sphincteric anal fistulas: a long-term outcome. J Gastrointest Surg. 2009; 13: 1116-1119.

[14] Buchanan GN, Owen HA, Torkington J, Lunniss PJ, Nicholls RJ, Cohen CR. Long-term outcome following looseseton technique for external sphincter preservation in complex anal fistula. Br J Surg. 2004; 91: 476-480.

[15] Hammond TM, Knowles CH, Porrett T, Lunniss PJ. The Snug Seton: short and medium term results of slow fistulotomy for idiopathic anal fistulae. Colorectal Dis. 2006; 8: 328-337.

[16] Polat FR. Rectosigmoidoscopy: Retrospective Evaluation of 295 Cases. Kafkas J Med Sci. 2011; 1: 21-4.

[17] Theerapol A, So BY, Ngoi SS. Routine use of setons for the treatment of anal fistulae. Singapore Med J. 2002; 43 : 305-307. 